\title{
Planning for diversity in an era of social change
}

\author{
Claire Colomb and Mike Raco
}

Quote as: Colomb, C. and Raco, M. (2018) Planning for diversity in an era of social change, in Ferm, J. and Tomaney, J. (eds) Planning Practice: Critical Perspectives from the UK. London: Routledge, pp. 174-188.

This chapter focuses on the relationship between the planning system and the ethnic, cultural, religious and demographic diversity which has arisen as a result of post-war waves of migration to the UK. It examines the ways in which perceived forms of 'difference' arising from this diversity have been addressed in planning and urban policy. We first outline how 'ethnicity' is conceived in the UK, before assessing how planning theorists and practitioners have advocated new forms of "planning for diversity" since the 1980s, driven by a politics of recognition of difference. Such concerns have first been addressed through national legislative anti-discrimination and equality provisions. We then show how Local Planning Authorities (LPAs) have encouraged the participation of ethnic minority groups into planning processes and sought to address their specific needs, through both minority-targeted policies and area-based urban policies. Finally, the role of planning in creating spaces of (multicultural) encounter is addressed. The chapter concludes by contrasting normative calls for "planning for diversity" with the ambiguities, contradictory outcomes, dilemmas and challenges of doing so in practice.

\section{Conceptions of ethnic diversity in the UK}

Between 1948 and 1970 nearly half a million Caribbean migrants came to the UK, followed from the 1960s onwards by migrants from India, Pakistan, Bangladesh and East Africa. First mainly composed of Commonwealth citizens filling labour shortages, those migratory waves later became more diverse in terms of national origin and migration status. In the 2000s and 2010s, substantial migration from Central and Eastern Europe was facilitated by the accession of 10 new countries to the European Union, with just under one million Polish nationals residing in the UK in 2016. In 1991 a question on 'ethnic group membership' was introduced in the census, in contrast with most European countries which do not collect ethnic or racial data. The categories used to capture differences of origin in social statistics and public policy do not take stock of 'true and authentic' identities, but are 'socially constructed, influenced by existing (and shifting) power relationships, national images and stereotypes, legal procedures and historical paths' (Simon and Piché, 2012: 1358). Collecting such data raises a dilemma: does 'distinguishing and characterizing populations according to their ethnic origins constitute a risk of stigmatization or is it, on the contrary, an asset for measuring and explaining discrimination and for demanding more inclusive policies?' (Ibid.: 1358). The acronym Black and Minority Ethnic (BME) is used here to refer to individuals who self-describe as not "White" British" in the UK census (they may be British citizens or foreign nationals). The terms 'ethnicity' and 'race' are thus not used as objective categories, but as social and relational constructs which structure public action (Thomas, 2000). Acknowledging the 
critiques of these analytical categories (e.g. Brubaker, 2004; Vertovec, 2007), we later reflect on the problems posed by their use in planning and urban policy.

In 2011 the BME population (see Figure 11.1 for a breakdown) represented just under $20 \%$ of the population of England and Wales, but was unevenly distributed across the territory: half of it lived in three cities - London, Birmingham, and Manchester. London's BME population reached $55 \%$ in 2011 . There is thus a particularly urban dimension to the challenges of a more diverse society - although not exclusively ${ }^{i}$. Within cities, BME households tend to be concentrated in particular areas where the proportion of BME population is higher than average, something referred to by sociologists - in a descriptive, non-normative way - as ethnic 'segregation', i.e. the unequal distribution of a particular kind of attribute, in this instance ethnicity, among spatially defined population aggregates. In British cities, however, areas of BME concentration are usually ethnically mixed.

The ways in which European states have dealt with the integration of migrants into their national society have differed significantly, reflecting different 'public philosophies of integration' (Favell, 1998) which evolved over time. In the UK, there was a gradual 'racialisation of immigration' in British politics: non-white immigration was increasingly portrayed as problematic and in need of controls, introduced in 1962. Since then, successive national governments have combined (variable degrees of) restrictions on the entry of new migrants with the promotion of 'race equality', 'anti-discrimination', and later 'equal opportunities' for the resident BME population (Thomas, 2008). At the local level, from the 1970s onwards several local authorities began to develop 'pluralist' or 'multiculturalist' policies (e.g. in Birmingham, Leicester, Sheffield or London), often more progressive than those of the national government. Indeed some of the most significant and effective forms of 'planning for diversity' have been developed at the local level, more specifically in superdiverse cities (Raco et al., 2017). In London, the ethnic and cultural diversity of the population has been embraced and marketed in positive terms by successive mayors. This ostensible celebration - often underpinning an agenda of economic competitiveness - has recently stood in stark contrast with the national government's increasingly negative views on migration and diversity, in particular in the wake of the Brexit referendum and increased anxieties about terrorism.

Figure 11.1: Ethnic groups other than White in England and Wales, 1991-2001-2011 census data.

Note: the 'Other' groups are: Mixed - 1,224,400 (+82\%); Other Asian - 835,720 (+238\%); Other Black - 280,437 (+186\%); Arab - 230,600 (not measured before 2011); Other - 333,096 (+46\%) (this excludes White Irish and White Other categories).

Source: Jivraj and Simpson, 2015: 21 (reproduced with permission)

\section{The politics of difference and the case for diversity-sensitive planning}

In the 1960s, critical voices began to challenge the post-war 'rational comprehensive planning' consensus which dominated Western planning practice. Planning, as an instrument of state power, was criticized by Marxist and neo-Weberian scholars for reproducing patterns of inequalities or discrimination against particular groups (e.g. ethnic minorities or lowincome groups) and for marginalising their needs. In the UK, Rex and Moore's (1967) study of 
housing and race relations in Birmingham showed how bureaucratic procedures for council housing allocation systematically disadvantaged BME individuals. Pahl (1975) further investigated the role of 'urban gatekeepers', such as planners or estate agents, who through the allocation of urban resources can favour or disadvantage particular individuals. This was compounded by portrayals of 'authoritarian' and 'insensitive' planners who destroyed communities through top-down slum clearance (Dennis, 1970, 1972) - practices which became increasingly challenged by grassroots mobilisations. Thomas (2000), in his extensive work on the topic, argues that British planning practice has historically been 'socially conservative', with key planning ideas such as urban containment, rural conservation and New Towns contributing to sustaining racial segregation in inner cities and a 'White' view of Englishness.

In the 1970s and 1980s, concerns for the 'politics of recognition' and 'difference' took centrestage in both critical social theory and progressive political debates. Post-structuralist, postcolonial, and feminist thinkers shifted the traditional focus on class inequalities towards the need for recognition and empowerment of individuals and groups marginalized because of their ethnicity, gender, age, culture, religion, (dis)ability or sexuality (Young, 1990). In this context, the built environment and planning practices were shown to reflect dominant power structures and reproduce systemic inequalities (Sandercock, 2003). In the UK a minority of activist planners began to push the Royal Town Planning Institute (RTPI) to work on issues of gender and racial equality. The RTPI, in partnership with the Commission for Racial Equality (CRE), published an extensive report in 1983 which highlighted how planning had been an arena for unwittingly discriminatory practices or colour-blind approaches deemed inadequate. In the decade that followed, however, little progress was made in implementing its recommendations (Krishnarayan and Thomas, 1993). A further study of LPA practices with regards to BME groups (Loftman and Beazley, 1998) showed that only 3\% of LPAs in England, Scotland and Wales monitored the impact of planning policies on BME groups, $10 \%$ undertook research on BME planning needs, $14 \%$ had mechanisms for direct contacts with BME group, and $13 \%$ had specific planning policies (see Ellis, 2001, for a similar review in Northern Ireland).

\section{The evolution of anti-discrimination and equality legislation and its application to planning}

The Race Relations Act (RRA) - the first legislation of its kind in Western Europe - was first passed in 1965 and later revised in 1968, 1976 and 2000. It made it unlawful to discriminate against anyone on grounds of race, colour, nationality (including citizenship), ethnic or national originii, and the 1976 version referred explicitly to land use planning. This legislation has helped to fight against direct racial discrimination in planning - for example the refusal to grant planning permission to an Indian applicant for a takeaway restaurant due to concerns over the smell of food (Thomas, 2000), or against racist representations in public consultations (RTPI, 1996). Yet it has been of 'little practical use in preventing the application of planning regulations in ways that are blind to differences of culture and ethnicity' (Gale and Naylor, 2002: 390).

The Equality Act of 2010 brought together 116 separate pieces of anti-discrimination legislation. Article 149 reiterates the so-called 'public sector equality duty' to actively promote equality of opportunity and tackle direct and indirect discrimination in relation to 
nine 'protected characteristics': age, disability, gender, race, religion and belief, pregnancy and maternity, marriage and civil partnership, sexual orientation and gender reassignmentiii. This duty is reflected in the RTPI Code of Professional Conduct and Statement of Ethics and Professional Standards, to which all chartered planners must pledge. In the case of planning, indirect discrimination may occur 'when a criterion, requirement or condition is applied to everyone, but in practice a much smaller proportion of some groups can comply with it than is the case for others' (ODPM, 2005: 31), for example by imposing a requirement to write representations on planning applications in writing and in English. Indirect discrimination 'does not imply that individuals in an organisation are necessarily evil or racists', but reveals an ignorance about the real effects of policies and procedures (Thomas, 2000: 16).

Public bodies have used various tools to demonstrate how they meet the public sector equality duty, for example through 'Race Equality Schemes' and 'Race Equality Impact Assessments' (both created by the Race Relations (Amendment) Act 2000). Such assessments aim to encourage public bodies, including LPAs, to anticipate the impact of proposed plans and policies on BME groups (although they are no longer a compulsory legal requirement under the Equality Act 2010). There is no systematic study of the application of such assessments in the field of local planning. They seem to have been used unevenly, with some uncertainty, often as a tick-boxing exercise within a broader 'politics of documentation' in which 'doing the document' rather than 'doing the doing' is more important (Ahmed, 2007). In 2012 the Conservative government announced a review of the public sector equality duty, viewing such assessments as time-consuming and often unnecessary bureaucratic exercises.

Nevertheless, the legally enshrined 'public sector equality duty' has opened the possibility for individuals and organisations to challenge public bodies through judicial reviews in front of the courts. There are only few examples of this process of 'judicialisation' in the planning field (Halford, 2010). In the $R$ (Harris) $v$ London Borough of Haringey (Equality and Human Rights Commissions intervening) [2010] EWCA Civ 703 case, the Court of Appeal quashed the decision of Haringey Borough Council to grant planning permission for the development of a site (known as Wards Corner) on the grounds that the Council failed to discharge its duty to 'promote equality of opportunity and good relations between persons of different racial groups' (section 71 of the RRA). The Court ruled that a LPA must prove it has properly assessed the likely impacts of a proposed scheme on different racial groups (even if it would still be able to grant planning permission if, on balance, the proposals were deemed acceptable).

Legislation is a necessary but insufficient step for change, and needs to be complemented by the integration of equality opportunities and diversity principles into everyday policies and practices at a range of spatial scales (Reeves, 2005). It is not until the arrival of New Labour into government in 1997 that the word 'diversity' appeared in national planning guidance, with the publication of a research report (Booth et al., 2004) and good practice guide (ODPM, 2005) which stated that 'the culture of planning should recognise, respect, value and harness difference' (p. 14). The guide encouraged LPAs to recognise diversity through research and data gathering, effective community engagement, the integration of diversity objectives in planning policies and procedures, and changes in organisational culture. The government additionally called for increasing the recruitment of under-represented categories into planning. In 2000 the proportion of planners from a BME background was less than $2 \%$ (CABE, 2005). In 2010, only 3.3\% of RTPI members defined themselves as non-White (Ellis et al., 
2010); as of May 2017, this share had increased to $7.87 \%^{\text {iv }}$. The Tomorrow's Planners initiative was set up in the early 2000s by the Planning Inspectorate, (then) ODPM and RTPI with the aim to bring $500 \mathrm{BME}$ individuals into the planning profession through a placement and educational programme developed in partnership with LPAs, planning consultancies and universities. The scheme benefited approximately 90 BME planners, but was stopped in $2007^{\vee}$. However, in 2015/16, 21\% of UK-domiciled students enrolled on RTPI-accredited courses were from a BME group ${ }^{\text {vi }}$.

\section{Engaging the BME population in participatory processes}

As calls for public participation in planning became stronger in the 1970s, so too were efforts to include BME groups often referred to as 'culturally' distinct, 'hard-to-reach' or marginalized (Beebeejaun, 2006). Some of the barriers that prevent BME individuals from engaging with planning include language, lack of educational capital to navigate the complexity of the system, time pressures due to multiple employment and care responsibilities, or feelings of disenfranchisement. LPAs have used a variety of means to encourage BME participation such as: translating information materials into foreign languages, inviting BME representatives to participate in public events, organising BME-targeted participatory activities, setting up a forum of "representative" BME organisations, or more rarely appointing a BME liaison officervii.

Whilst this is preferable to a situation which ignores BME voices, such participatory approaches are often fraught with ambiguities, flaws and unintended adverse effects. The adoption of ethnic categories to structure consultation approaches on the basis of the Census classifications and the 'protected characteristics' of the 2010 Equality Act naturalises identity categories which are in reality changing, complex, mixed, hybrid, or even irrelevant for the individuals concerned. Members of an ethnic group are assumed to have culturally distinctive and relatively homogeneous needs, values and lifestyles which are stable over time and shared by all members (Thomas, 2008). Such assumptions may reinforce stereotypes in the policy-making process and ignore internal group differences (Beebeejaun, 2006). Recent research has indeed shown that there is a significant diversification of the BME population in terms of class, income, age, disability, gender, or lifestyles - captured by the notion of 'superdiversity' (Vertovec, 2007). However, public policies and service delivery are still framed by a simple ethnicity-focused approach that neglects new relevant variables such as 'differential immigration statuses and their concomitant entitlements and restrictions of rights, divergent labour market experiences, discrete gender and age profiles, patterns of spatial distribution, and mixed local area responses by service providers and residents' (Vertovec, 2007: 1025).

Moreover, BME voices are often channelled by 'advocacy agents' (e.g. NGOs fighting for particular groups) or by representatives who claim to speak on behalf of a supposedly cohesive 'community'. Such an approach has been criticized for unwittingly fostering separation and for giving disproportionate power to older 'community leaders' who can silence particular voices within an ethnic "community". Beebeejaun's analysis of BME engagement in two LPAs (2006) shows that male, business-oriented and socially conservative voices dominated the process, at the expense of women and younger people. Finally, there is often a problematic shortfall between 'initial participatory discussions involving ethnic minorities and concrete inclusion of their views and opinions in either the policy or the built 
environment' (Beebeejaun, 2012: 546), because the discretionary nature of the UK planning system allows planners to determine whether particular matters are planning-related or not.

\section{Responding to the needs of spatially-concentrated BME populations: planning and urban policy responses}

BME households exhibit clear patterns of spatial concentration in particular areas, which are explained by a combination of structural-economic factors (e.g. lower incomes), discrimination, and ethnic-cultural preferences (Phillips, 2007; Phillips and Harrison, 2010). In those areas, the impact of migrants and BME groups on the demand for services and amenities has been a central aspect of debates on planning for diversity. In the immediate post-war era, no attention was paid to the specific needs of new migrants. Various dispersal initiatives sought, on the contrary, to 'dilute' the presence of BME households (Phillips and Harrison, 2010), for example through the planned dispersal of East African Asian refugees in the early 1970s. Birmingham City Council applied a dispersal strategy in social housing allocation between 1969 and 1975, eventually outlawed under the 1976 RRA. Dispersaloriented approaches were gradually abandoned, with the exception of the mandatory dispersal policy still imposed on asylum seekers.

From the 1970s onwards, attempts were made to address the needs of spatially-concentrated BME populations through two main types of approaches. Firstly, a number of Labour-led cities committed to anti-racist and multiculturalist agendas (such as the Greater London Council or Leicester) sought to respond to the qualitatively different needs arising from the cultural or religious practices/values of specific ethnic groups, through targeted - and at times controversial - policies. In the field of housing, for example, the prevalence of multigenerational households among Bangladeshi or Pakistani groups, or of large family units in Haredi Jewish communities, were addressed through the modification of local planning policies to facilitate larger housing units (as in the London Borough of Hackney, where house extensions were conditionally allowed in residential areas where the Haredi community is concentrated). In parallel, the growth of BME-run housing associations was encouraged from the 1980s onwards viii - an almost internationally unique example of state-funded institutionalised self-management on ethnic or religious lines (Flint, 2010). Another area of adaption of local planning policy has been the provision of non-Christian places of worship. Following evidence of significantly higher rates of refusal for applications for the construction of, or conversion of residential buildings into, mosques (Gale, 2008), some LPAs (e.g. Leicester City Council in 1977) changed local policies to help faith communities gain planning permission for suitable premises.

However, some of the needs of BME groups do not arise from different cultural features per se, but rather from their socio-demographic profile - often on average younger, or poorer, than the rest of the population (Thomas, 2000). In areas of high concentrations of deprivation, such needs have been addressed by a second type of approach: 'area-based' urban policies targeting deprived neighbourhoods defined on the basis of statistical indicators measuring deprivation or unemployment. As such areas are often those with a high rate of BME residents, the latter were indirectly supposed to benefit from such policies. In 1968, two weeks after Enoch Powell's infamous "River of Blood" speech, the Labour government launched the Urban Programme to support deprived inner-city areas - the first of a long series 
of urban policy initiatives set up by successive governments. Such interventions are anchored in debates about so-called 'neighbourhood effects': whether where a person lives affects (in a positive or negative way) their opportunities and life chances above and beyond individual characteristics, and whether public policy should intervene to dissolve concentrations of deprived (and/or BME) households in particular neighbourhoods. With few exceptionsix, however, no urban policy initiative was ever formulated with an explicit focus on BME populations, for fear of alienating the white electorate (Atkinson and Moon, 1994). The focus was on concentrations of deprivation.

The property-led urban regeneration initiatives set up by the Conservative governments in the 1980s (e.g. Urban Development Corporations) paid scant attention to BME needs, and their supposed 'trickle-down effect' failed to materialize for low-income groups (Brownill et al., 1996). In 1997, the New Labour government set up new initiatives to address social exclusion in the poorest neighbourhoods of England (the New Deal for Communities), acknowledging that addressing racial discrimination in such programmes was essential, although this aspect was found to be lacking in practice (CRE, 2007). In parallel, the policy objective of 'mixed communities' became central to the 'Urban Renaissance' agenda, based on the assumption that mixing different types of housing tenure would lead to greater social mix and positive effects for deprived neighbourhoods and their residents (Lupton and Fuller, 2009). This was to be achieved through the redevelopment of low-income areas of private housing in Northern English cities (Housing Market Renewal), and the partial demolition and redevelopment of social housing estates seen as 'problematic'. Such programmes have generally not led to greater social interaction or significant positive socio-economic effects for deprived neighbourhoods and residents (Cheshire, 2009; Tunstall and Lupton, 2010). They have often had negative impacts on low-income and/or BME populations through the direct displacement of households and businesses (Lees, 2014).

Debates on BME concentrations took a new turn in 2001, after episodes of urban unrest between young people from different ethnic groups in Bradford, Burnley and Oldham. Official reports attributed those 'riots' to divisions created by the 'self-segregating tendencies' of working-class British Asians and Whites, depicted as living 'parallel lives' (Cantle, 2001). This took place in the context of a growing backlash against 'multiculturalist approaches' (Vertovec and Wessendorf, 2010) by both conservative and progressive commentators. The terrorist attacks perpetrated in the USA in 2001 and in London in 2005 further compounded public anxieties about the supposed self-segregation of Muslims (Philipps, 2006) and led to a new policy agenda for 'community cohesion' and 'national integration'. After 2010, Conservativeled governments stopped funding national urban policy initiatives in deprived neighbourhoods. In the context of public anxieties about the socio-economic impacts of globalisation and migration on cities and regions, the rise of far-right political parties, and the fear of terrorism, the government has strengthened its discourse on national identity, integration and shared 'British values'.

Four decades of area-based urban policies in the UK have altogether had a small effect on the reduction of inequalities between places and people, and have not significantly addressed the way racial discrimination adversely affects the life chance of BME groups (Brownill and Thomas, 2001), who still suffer from stigmatization and higher rates of deprivation. This points to a crucial challenge at the heart of planning and regeneration 
practice: the extent to which one can produce positive local socio-economic change through physical, area-based interventions which do not always address the root causes of socioeconomic or racial inequalities (Cheshire, 2009).

\section{Planning for spaces of (multicultural) encounter}

For Sandercock (2003), the co-existence of different cultures requires engagement between people who perceive themselves as different, the recognition of the porosity and internal heterogeneity of cultures, and openness to the possibility (and reality) of mutual influence between them. This is only possible in particular spaces of encounter and interaction. This includes open and green spaces (parks, allotments and sports grounds), publically-owned facilities (libraries or schools) or community-run facilities. Privately-owned, but publically accessible, commercial or leisure spaces such as cafés, cinemas, restaurants or shops and services for daily needs also play a key role. A common and often unchallenged assumption in planning practice is that the provision of, and improvements to, such spaces will lead to more and better social interactions. There is indeed an abundant literature on the role of urban design in fostering (or hindering) positive behaviours and social interactions (e.g. New Urbanism). Moreover, in cities such as Leicester, Birmingham or London, local authorities have purposefully used public spaces to celebrate expressions of 'difference' by supporting 'world cultures, minority voices, ethnic pluralism, and alternative local histories' (Amin, 2002: 968), for example through festivals. In some areas, particular markers of ethnic "culture" or entrepreneurship, such as restaurants, have been marketed as assets for neighbourhood branding and revitalization (see Shaw et al., 2004 on London's 'Banglatown'). The commodification of ethnic cultures that this entails is not without critics, who note that a 'Steel Band, Sari and Samosa' approach can superficially celebrate difference without addressing questions of inequality (Perrons and Skyers, 2003).

Yet public spaces are not exempt from conflicts and exclusions, as they accommodate multiple users who may clash with one another. In a city like London, daily encounters with 'commonplace diversity' (Wessendorf, 2014) in public, institutional and associational spaces is usually experienced and valued positively, although some groups (women, older people, BME youth) often have negative perceptions of safety. More broadly, the transformation of public spaces under multiple processes of privatization, commodification, exclusionary zoning, surveillance and policing has had significant impacts on the social diversity allowed in such spaces - a process compounded by contemporary fears about crime, social disorder and terrorism. While safer spaces may encourage greater social interaction, strengthened practices of surveillance and policing through CCTV, police controls or defensive urbanism are shown to disproportionally affect certain (already vulnerable or discriminated against) groups, for example young Black or Asian males.

For those reasons, planning should not solely be concerned with providing 'grand public spaces' where strangers can mingle (Amin, 2002). It should also resource 'situations and institutions through which people can make contact on the basis of shared activities and interests which might transcend fixed identities such as gender, race, and class' (Iveson and Fincher, 2011: 413).I Ideally, these are sites of 'convivial encounters' (Neal et al., 2013) where 'prosaic negotiations' are compulsory (Amin, 2002), such as the workplace, schools, universities, sports clubs, public libraries and drop-in centres. The UK planning system plays 
a key role in the delivery of such spaces, through the plan-led allocation of sites for social infrastructure, development control decisions, and mechanisms for planning gain. Yet in an era of austerity and deregulation, LPAs are increasingly limited in this task. Many have had to close down public facilities such as libraries, or cut subsidies and stop the lease of public buildings to community organisations which perform key services for particular social groups. More generally, in a city like London, planners have lacked powers to control the rapid transformation of the built environment in the face of strong development pressures. The combination of market-led gentrification and state-led regeneration often threatens existing patterns of socio-economic and ethnic diversity. This has generated grassroots struggles to preserve sites central to the life and identity of particular BME groups (e.g. Afro-Caribbean culture in Brixton or Latin American culture in Elephant \& Castle).

\section{Conclusion}

This chapter has discussed how UK planning and planners, at the national and local level, have responded to the diversification of British society which arose from waves of migration. The examples of planning for a more diverse society mentioned here show that there are significant challenges between normative calls for 'planning for diversity', and the reality of actually doing so in practice, with difficult, politically and socially contentious decisions to be made by planners and policy-makers. In law-making, public policy design and resource allocation, there is a tension between the universal and equal treatment of all citizens, and the need to 'recognize' difference (especially when it is a source of inequality) by targeting specific groups. An equal distribution or treatment may be 'unfair', and a fair distribution or treatment may be 'unequal'. Planning practitioners cannot simply 'accommodate' or 'embrace' diversity as such, they have to distinguish between 'desirable and undesirable', 'just or unjust' forms of diversity and homogeneity (Fincher and Iveson, 2008: 2-3). According to Fincher and Iveson (2008), this means combining three social logics of 'planning for a just diversity': redistribution, to plan for the redress of disadvantage and inequality rooted in class; recognition, to define the attributes of (diverse) groups of people so that their needs can be met; and encounter, through which the interaction of individuals are 'planned for' in order to offer opportunities for increased sociality.

The increasing focus on the recognition of 'difference' and 'diversity' in public policy should not mask fundamental questions of socio-economic and class inequalities (Benn-Michaels, 2008). There is a danger that privileging identity politics shifts attention away from some of the key processes that generate contemporary inequalities, such as the functioning of labour and housing markets and/or the promotion of development programmes that prioritise economic returns and the creation of gentrified urban environments. Moreover, a focus on ethnicity as marker of 'difference' may underplay the intersections between class, ethnicity, culture, and place that shape the lives of individuals and communities, and the need to shift towards a relational, rather then essentialist, approach to identity. A stronger emphasis on understanding such inter-sectionalities may therefore provide a fruitful way of thinking about future planning priorities, so that they become more focused on the root causes, rather than the symptoms, of inequality (Valentine and Sandgrove, 2012). 


\section{Acknowledgements}

The authors would like to thank the editors, Jamie Kesten, and Tatiana Moreira de Souza for their comments on earlier versions of this chapter. The research received funding from the European Union's Seventh Framework Programme for research, technological development and demonstration under Grant Agreement No 319970 - DIVERCITIES. The views expressed in this publication are the sole responsibility of the authors and do not necessarily reflect the views of the European Commission.

\section{References}

Ahmed, S. (2007) 'You end up doing the document rather than doing the doing': diversity, race equality and the politics of documentation, Ethnic and Racial Studies, 30(4): 590609.

Amin, A. (2002) Ethnicity and the multicultural city: living with diversity, Environment and Planning A, 24: 959-80.

Atkinson, R. and Moon, G. (1994) Urban Policy in Britain. Basingstoke: Macmillan.

Beebeejaun, Y. (2006) The participation trap: The limitations of participation for ethnic and racial Groups, International Planning Studies, 11(1): 3-18.

Beebeejaun, Y. (2012) Including the excluded? Changing the understandings of ethnicity in contemporary English planning, Planning Theory and Practice, 13(4): 529-48.

Benn-Michaels, W. (2008) Against diversity, New Left Review, 52, 33-36.

Booth, C., Batty, E., Gilroy, R., Dargan, L., Thomas, H., Harris, N. and Imrie, R. (2004) Planning and Diversity. Research into Policies and Procedures. London: Office of the Deputy Prime Minister.

Brownill, S. and Thomas, H. (2001) Urban policy deracialized? in Yiftachel, O., Little, J., Hedgcock, D. and Alexander, I. (eds) The Power of Planning. Dordrecht: Kluwer, pp. 189203.

Brownill, S., Razzaque, K., Stirling, T. and Thomas, H. (1996) Local governance and the racialisation of urban policy in the UK: the case of UDCs, Urban Studies, 33(8): 1137-55.

Brubaker, R. (2004) Ethnicity without Groups. Boston: Harvard University Press.

CABE (2005) Black and Minority Ethnic Representation in the Built Environment Professions. London: Centre for Ethnic Minority Studies, Royal Holloway, University of London.

Cantle, T. (2001) Community Cohesion. A report of the Independent Review Team. London: Home Office.

Cheshire, P. (2009) Policies for mixed communities: faith-based displacement activity? International Regional Science Review, 32(3): 343-75.

CRE (2007) Regeneration and the Race Equality Duty. Report of a Formal Investigation in England, Scotland and Wales. London: CRE.

Dennis, N. (1970) People and Planning. London: Faber.

Dennis, N. (1972) Public Participation and Planners' Blight. London: Faber.

Ellis, G. (2001) The difference context makes: planning and ethnic minorities in Northern Ireland, European Planning Studies, 9(3): 339-58.

Ellis, G., Murtagh, B. and Copeland, L. (2010) The Future of the Planning Academy. London: RTPI.

Favell, A. (1998) Philosophies of Integration: Immigration and the Idea of Citizenship in France and Britain. Basingstoke: Macmillan. 
Fincher, R. and Iveson, K. (2008) Planning and Diversity in the City. Redistribution, Recognition and Encounter. Basingtoke: Palgrave.

Flint, J. (2010) Faith and housing in England: promoting community cohesion or contributing to urban segregation? Journal of Ethnic and Migration Studies, 36(2): 257-74.

Gale, R. (2008) Locating religion in urban planning: beyond 'race' and ethnicity? Planning Practice and Research, 23(1): 19-39.

Gale, R. and Naylor, S. (2002) Religion, planning and the city: the spatial politics of ethnic minority expression in British cities and towns, Ethnicities, 2(3): 387-409.

Halford, J. (2010) The Equality Act and its impact on Planning Law. London: Environmental Law Foundation.

Iveson, K. and Fincher, R. (2011) 'Just diversity' in the city of difference, in Bridge, G. and Watson, S. (eds) The New Blackwell Companion to the City. Oxford: Blackwell, pp. 40718.

Jivraj, S. and Simpson, L. (2015) How has ethnic diversity grown? In: Jivraj, S. and Simpson, L. (eds) Ethnic Identity and Inequalities in Britain: The Dynamics of Diversity. Bristol: Policy Press, pp. 19-31.

Krishnarayan, V. and Thomas, H. (1993) Ethnic Minorities and the Planning System. London: RTPI.

Lees, L. (2014) The urban injustices of New Labour's 'new urban renewal': the case of the Aylesbury Estate in London, Antipode, 46(4): 921-47.

Loftman, P. and Beazley, M. (1998) Race Equality and Planning. London: Local Government Association.

Lupton, R. And Fuller, C. (2009) Mixed communities: a new approach to spatially concentrated poverty in England, International Journal of Urban and Regional Research, 33(4): 1014-28.

Neal, S., Bennett, K., Cochrane, A., and Mohan, G. (2013) Living multiculture: understanding the new spatial and social relations of ethnicity and multiculture in England, Environment and Planning C, 31(2): 308-23.

ODPM Office of the Deputy Prime Minister (2005) Diversity and Equality in Planning. A good practice guide. London: ODPM.

Pahl, R. (1975) Whose City? And Further Essays on Urban Society, $2^{\text {nd }}$ ed. Harmondsworth: Penguin.

Perrons, D. and Skyers, S. (2003), Empowerment through Participation? Conceptual Explorations and a Case Study, International Journal of Urban and Regional Research, 27(2): 265-85.

Phillips, D. (2006) Parallel lives: challenging discourses of British Muslim self-segregation, Environment and Planning D, 24(1): 25-40.

Phillips, D. (2007) Ethnic and racial segregation: a critical perspective, Geography Compass, 1(5): 1138-59.

Phillips, D. and Harrison, M. (2010) Constructing an integrated society: historical lessons for tackling Black and Minority Ethnic housing segregation in Britain, Housing Studies, 25(2): 221-35.

Raco, M., Kesten, J., Colomb, C., and Moreira de Souza, T. (2017) DIVERCITIES: Dealing with Urban Diversity: The case of London. Utrecht: Utrecht University, Faculty of Geosciences. Online: https://www.urbandivercities.eu/london-city-book/.

Reeves, D. (2005) Planning for Diversity. London: Routledge. 
Rex, J. and Moore, R. (1967) Race, Community and Conflict: A Study of Sparkbrook. London and New York: Institute of Race Relations.

RTPI Royal Town Planning Institute (1996) Planning Authorities and Racist Representations. London: RTPI.

RTPI / CRE (1983) Planning for a Multi-Racial Britain. London: RTPI.

Sandercock, L. (2003) Cosmopolis II: Mongrel Cities in the 21st Century. London: Continuum.

Shaw, S., Bagwell, S., and Karmowska, J. (2004) Ethnoscapes as spectacle: reimaging multicultural districts as new destinations for leisure and tourism consumption, Urban Studies, 41(10): 1983-2000.

Simon, P. and Piché, V. (2012) Accounting for ethnic and racial diversity: the challenge of enumeration, Ethnic and Racial Studies, 35(8): 1357-65.

Thomas, H. (2000) Race and Planning: the UK Experience. London: UCL Press.

Thomas, H. (2008) Race equality and planning: a changing agenda, Planning Practice and Research, 23(1): 1-17.

Tunstall, R. And Lupton, R. (2011) Mixed Communities. Evidence Review. London: DCLG.

Valentine, G. and Sandgrove, J. (2012) Lived difference: a narrative account of spatiotemporal processes of social differentiation, Environment and Planning A, 44, 2049-63.

Vertovec, S. (2007) Super-diversity and its implications, Ethnic and Racial Studies, 30(6): 102454.

Vertovec, S. and Wessendorf, S. (eds) (2010) The Multiculturalism Backlash. London: Routledge.

Wessendorf, S. (2014) Commonplace Diversity. Social Relations in a Super-Diverse Context. Palgrave Macmillan.

Young, I. M. (1990) Justice and the Politics of Difference. Princeton: Princeton University Press.

\footnotetext{
${ }^{\mathrm{i}}$ The greatest relative growth in the BME population between 2001 and 2011 was in rural parts of England and Wales (Jivraj and Simpson, 2015).

${ }^{\text {ii }}$ Northern Ireland has separate legislation (see Ellis, 2001).

iii It is worth noting that 'affirmative action' or 'positive discrimination' (e.g. minimum quotas of BME

individuals), as used in the USA, are unlawful in Britain. However, 'positive action' measures are allowed to meet training, education or welfare needs.

iv Data supplied by the RTPI, 2/05/2017.

${ }^{v}$ Thanks to Chris Shepley (former head of the Planning Inspectorate) for sharing his recollections about the initiative he was instrumental in setting up.

${ }^{\text {vi }}$ Data supplied by the RTPI, 2/05/2017.

vii Beyond LPAs, a number of organisations have worked to assist disenfranchised groups in making their voice heard in relation to planning, such as Planning Aid, the (now defunct) Black Planners' Network, and the London Just Space network.

viii There were over 100 such associations in the mid-1990s, supported between 1986 and 1996 by funding from the Housing Corporation.

${ }^{\text {ix }}$ Exceptions were: Section 11 of the Local Government Act 1966 which created central government grants to support local authorities hosting high numbers of immigrants; and a small portion of funding created within the Urban Programme in 1974 for BME social and cultural projects.
} 